\title{
Determining the effectiveness of protective fences from explosions of terroristic orientation
}

\author{
Alexander Komarov ${ }^{1}$, Phan Tuan Anh ${ }^{1, *}$ \\ ${ }^{1}$ Moscow State University of Civil Engineering, 26, Yaroslavskoe Shosse, Moscow, 129337, Russia
}

\begin{abstract}
The article provides a general methodology for determining the effectiveness of protective fence against explosive devices of a terroristic nature. It also presents an example of using the developed methodology to create a more optimal solution for protective fence for a particular enclosure.
\end{abstract}

Keywords: protective fences, explosion, pressure, blast shock wave, probability of human casualty

\section{Introduction}

Protective fences (fences) are in places with massive congestions to reduce the probability of human casualty to explosive devices (ED) which are used for terroristic purposes. To evaluate the effectiveness of the protective screens (PS), it is necessary to determine in advance the following initial data: equivalent weight in TNT to the explosive substance (ES) in the explosive device; area of the protected territory and the permissible probability of a person being killed in the protected area.

The main damaging factors from explosive devices include an blast shock wave (BSW) accompanying the explosion; the fragmentation of the debris and fragments from the ED; significant thermal emission near the explosion; secondary damaging factors, which are associated with the destruction of the structures near the site of the explosion. This article examines the optimal geometric parameters for protective screens in terms of ensuring people's protection from BSW. Durability characteristics and the screen's efficiency for protection from debris in this article are not examined. Therefore, when carrying out calculations it is assumed that the screens are considered rigid and resistant to explosion.

\section{Method for determining the effectiveness of protective fences from explosions}

Let's take a look at the specifics of the calculation of the effectiveness of protective screens (PS) using the example of a protected territory located outside the parking lot, away from blast shock waves that form during explosions which can be located in a car in the parking lot.

\footnotetext{
* Corresponding author: ptuananh26789@gmail.com
} 
It is established that the source of threat, when the explosive device (ED) is delivered by car, the maximum mass of the explosive substance (ES) in TNT equivalent weight cannot exceed $50 \mathrm{~kg}$. In cases where there are visual inspections of a car, delivery of charges with greater mass may be excluded. The given mass of ED is compactly packed and during the explosion, it does not use any energy to open the caches (for example, opening the hidden cavities of the car, its trunk, etc.). I.e. in the parking lot, the biggest blast shock wave that can be formed is created in an above ground explosion of $50 \mathrm{~kg}$ of compactly packed TNT located in an open space.

To determine the protective screen's effectiveness, it is necessary to determine the parameters of the blast shock wave (BSW). For free spaces, the BSW parameters can be determined from empirical relations [1-4], and for cluttered spaces (there are protective screens on the BSW's path), it is necessary to use numerical calculation methods. To determine BSW's parameters, we use a numeric scheme from Godunov's scheme based on the breakdown of an arbitrary discontinuity [5-9].

Knowing temporal dependencies of the BSW into all points of space, one can determine the probability of an event: the complete destruction of buildings; average destruction of buildings; human casualties; eardrum rupture; human spatial movement due to BSW, etc.

The probability of human casualty was determined from known ratios using the probit function. The value of the probit function, which determines the probability of dealing damage (in this case, the probability of human casualty) is:

$$
P r_{1}=5-0.26 \cdot \ln V_{1}
$$

Where factor V1 equals:

$$
V_{1}=\left(\frac{17500}{P(P a)}\right)^{8.4}+\left(\frac{290}{I(P a \cdot s)}\right)^{9.3},
$$

Where $\mathrm{P}(\mathrm{Pa})$ is the maximum pressure in the BSW, $\mathrm{I}\left(\mathrm{Pa}^{*} \mathrm{~s}\right)$ - the momentum of the compression phase in the BSW [10,11].

\section{Calculation result}

Let us look at the results of the calculation for the first schematics of the location of the EDand the fence dimensions (Option 1).

It is established that the ED is located at a point with a coordinate $y=1.8 \mathrm{~m}$. The first fence with a height of $1.5 \mathrm{~m}$ is $1.2 \mathrm{~m}$ away from the charge $(\mathrm{y}=3 \mathrm{~m})$. This fence should destroy the BSW at the initial stage and perform its function of intercepting the fragments that arise during the explosion. The second fence height $4.5 \mathrm{~m}$ is located at a distance of $7.2 \mathrm{~m}$ from the charge $(\mathrm{y}=9 \mathrm{~m})$. The second fence should provide a reduction in the intensity of the BSW to an acceptable (safe) level on the outside of the enclosure, i.e. outside the parking lot. In the first arrangement option of fences, it is assumed that the space between the first and second fencing will be used only for driving cars in the parking lot. With this arrangement option of the protective screens parking will be carried out only after the first $(\mathrm{H}=1.5 \mathrm{~m})$ fence.

Fig.1 shows isolines of equal explosion pressure in the examined region with the first option of the fence arrangement. Additionally, Fig. 1 shows the location of the ES, the fences are shown and the points of the calculated temporal dependencies of the surplus pressure $\mathrm{P}(\mathrm{t})$ are marked.

From the figure below, it can be seen that the fence significantly reduces the levels of BSW outside the parking lot. The quantitative attenuation of the BSW is illustrated in Fig. 2 , where the ratio is given of the maximum levels of the BSW in the presence of a fence to the maximum levels of BSW in free space, i.e. without fencing. 
It can be easily seen that directly behind the fence, the parameters of the BSW is reduced by 5 times, because the ratio of the maximum levels of BSW in the presence of a guard to the maximum levels of BSW in free space is less than $20 \%$.

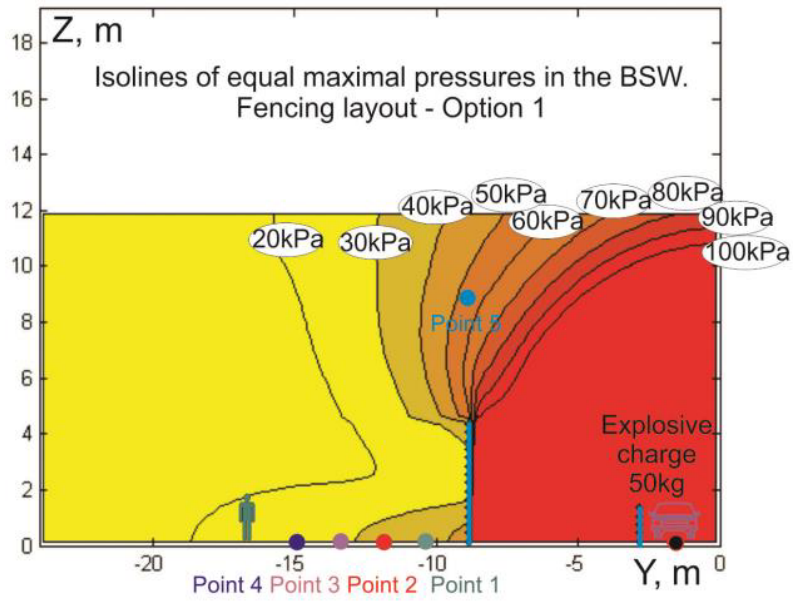

Fig.1. Isolines of equal pressurse in BSW. Option 1.

Here we have the levels of maximum pressures in the BSW at points $1-5: 37.2 ; 32.6$; $29.0 ; 25.9 ; 54.3 \mathrm{kPa}$.

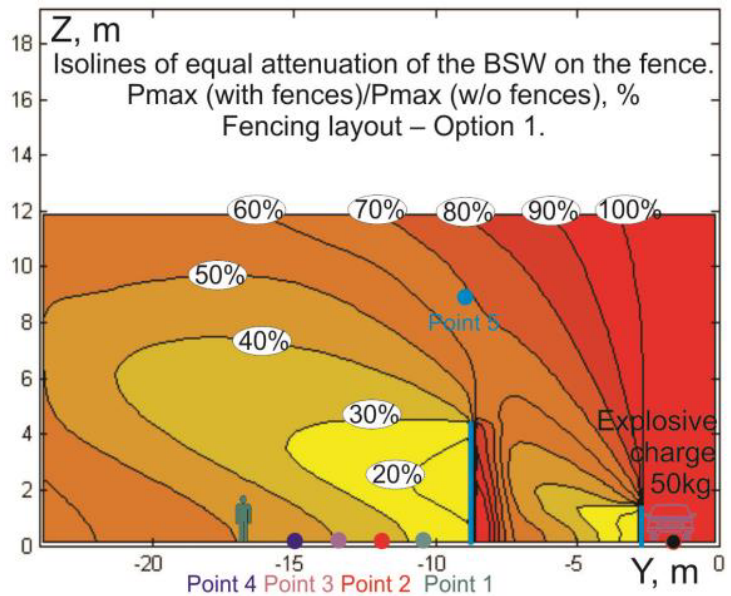

Fig.2.Isolines of equal attenuation of the BSW on the fence. Option 1

Levels of maximum pressures in the shock wave for the same points $1-5$, but in the absence of protective guards, respectively are equaled to: $134.6 ; 96.7 ; 73.7 ; 58.6 ; 78.9 \mathrm{kPa}$. The probability of human casualty at points $1-5$, determined by the relationships between (1) and (2), has the following values: $69.5 ; 52.7 ; 36.8 ; 24.8 ; 40.7 \%$.

Fig. 3 shows isolines of equal probabilities of human casualty in the presence of a guard in the first option. The probabilities of human casualty at points $1-5$, determined by the ratios between (1) and (2) and have the following values: $0 ; 0 ; 0 ; 0 ; 12.6 \%$. 


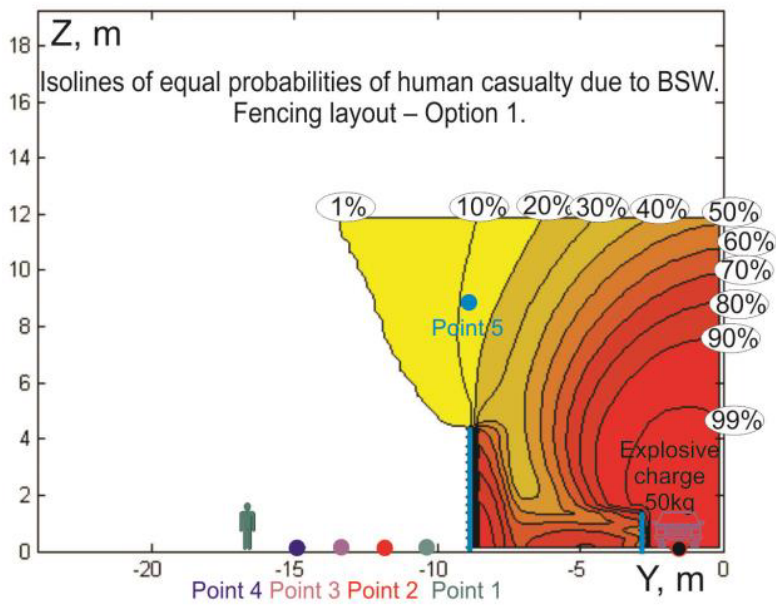

Fig.3. Isolines of equal probabilities of human casualty due to BSW. Option 1.

Thus, the calculations showed that the probability of human casualty outside the parking lot using the protective screens by option 1 would be close to zero. This type of fence can be used in places that require a wide ( $6 \mathrm{~m}$ or more) transport passage, i.e. this fencing design limits the use of parking space.

Now let us look at the effectiveness of protective fences for a situation where parking should be located closer to the fence. The second option of fencing design was examined, which assumes that the distance between the explosive charge and the fence is $4.2 \mathrm{~m}$, i.e. between a parked car and a fence, the journey is only $3 \mathrm{~m}$. There is only one fence and its height is $4 \mathrm{~m}$.

Let's take a look at the results of the calculations for the second schematic of the layout of the ED and the dimensions of the enclosure (Option 2). Fig. 4 shows isolines of equal explosion pressure in the examined region with the second option in the fence arrangement of the enclosure.

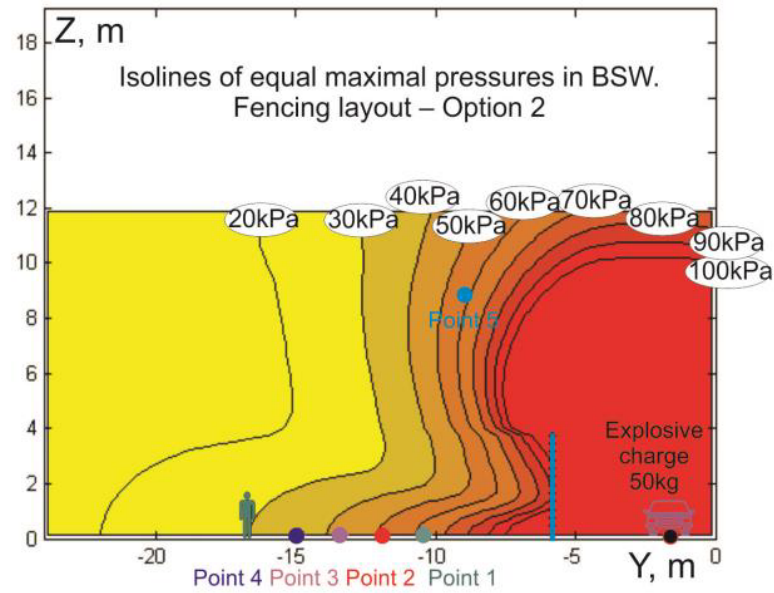

Fig. 4. Isolines of equal explosion pressures in BSW. Option 2. 
It can be seen from the figure that although the screen reduces the levels of the BSW outside the parking lot, but their numerical values are still quite large. The quantitative attenuation of the BSW is illustrated in Fig. 5.

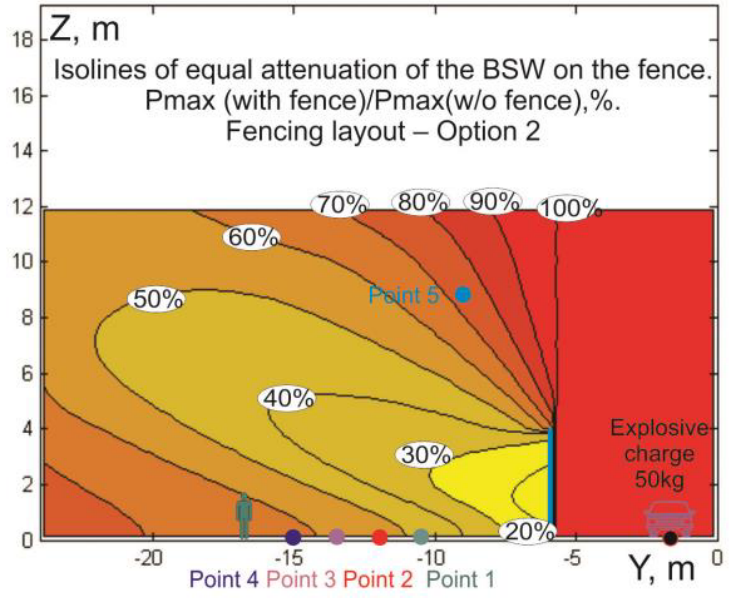

Fig. 5. Isolines of equal attenuation of the BSW on the fence. Option 2

Figure 5 shows the ratio of the maximum levels of BSW in the presence of a guard to the maximum levels of BSW in free space, i.e. without fencing.

Significant high levels of pressure outside the parking lot leads to an increase in the likelihood of deaths in the explosion of the ED in the parking lot.

Figure 6 shows the isolines of equal probabilities of human casualty in the presence of a guard in the second option.

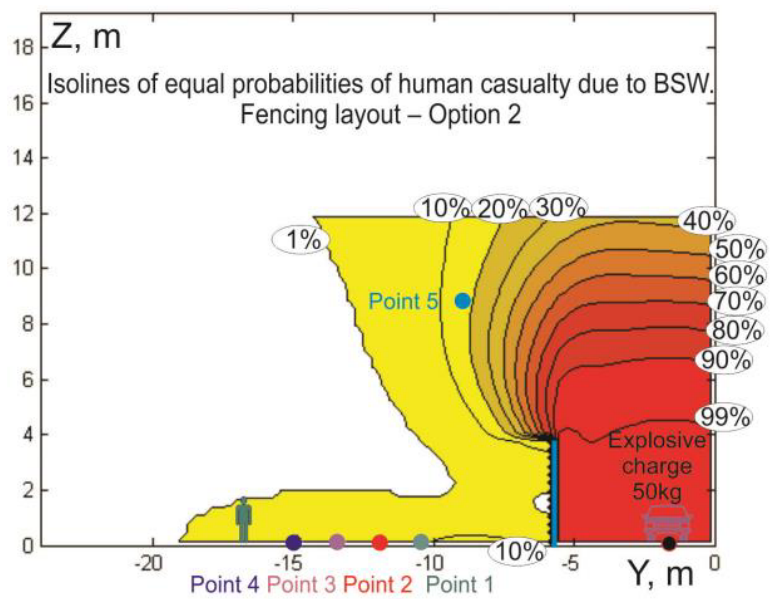

Fig. 6. Isolines of equal probabilities of human casualty due to BSW. Option 2.

From the figure above, it can be concluded that the probability of hitting people outside the parking lot at distances of $15-20 \mathrm{~m}$ from the fence will be more than $1 \%$, and in some places will reach $10 \%$, which is at an unacceptable level from the point of view of explosion safety.

Levels of maximum pressures in the BSW when using the enclosure of option 2 for points $1-5$ are respectively: $63.7 ; 51.6 ; 42.7 ; 36.0 ; 59.1 \mathrm{kPa}$. The probability of human 
casualty at the same points $1-5$ (with the second layout option of the fence) has the following values: $9.6 ; 7.2 ; 4.8 ; 3.2 ; 17.4 \%$.

To reduce the explosive pressure significantly outside the parking lot, it is possible, with the same dimensions, but it is necessary to place the fence at an angle to the horizon (making it inclined). The outing of the upper point should be $1.5 \mathrm{~m}$ (option 3 ).

Figure 7 shows the isolines of equal explosion pressure in the examined region using the third fence layout option in the enclosure.

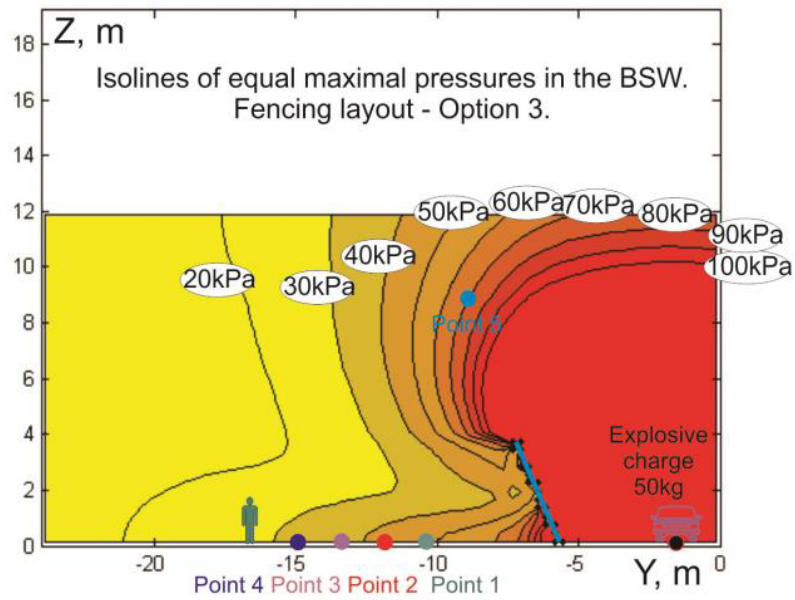

Fig. 7. Isolines of equal pressures in the BSW. Option 3.

From the figure above, it is seen that a slight slope of the fence leads to some reflection of the BSW, which reduces the levels of the BSW outside the parking lot.

In addition, with an inclined arrangement of the fence, the impact load is reduced, and the support structure is more resistant to impact loads.

Fig. 8 shows the isolines of equal probabilities of human casualty in the presence of a guard in the third option. From the data shown in Fig. 8, it can be interpreted that the probability of hitting people outside the parking lot at distances of 10-12 $\mathrm{m}$ from the fence is reduced to $1 \%$.

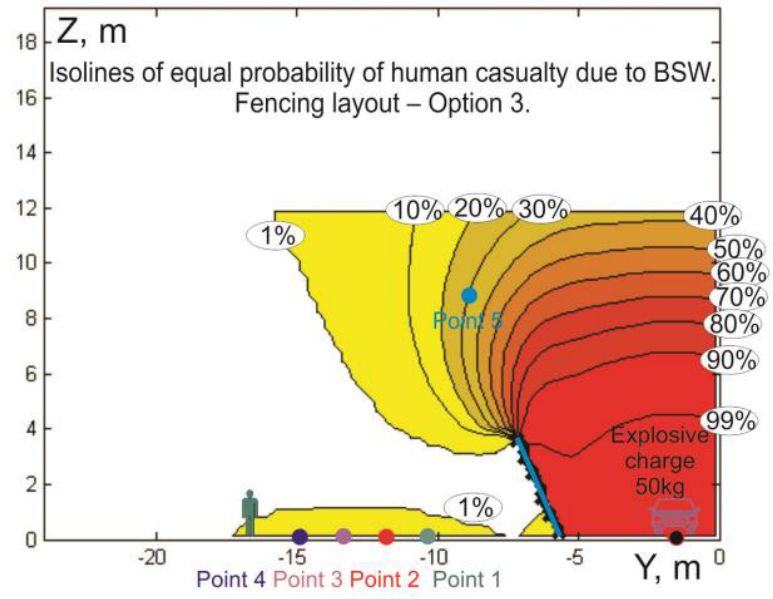

Fig. 8. Isolines of equal probability of human casualty due to BSW. Option 3. 
Levels of maximum pressures in the BSW when using the fence layout of option 3 for points $1-5$ are respectively equal to: $48.9 ; 43.0 ; 37.5 ; 32.6 ; 70.6 \mathrm{kPa}$. The probability of human casualty at the same points $1-5$ (with the third version of the fence) has the following values: $2.8 ; 3.0 ; 2.5 ; 1.9 ; 30.7 \%$.

Let us end on the procedure for selecting the necessary schematic of protective structures for the situation in question.

Following from the above calculations, reducing the probability of human casualty behind the fence to zero leads to certain difficulties when using parking spaces and certain costs for the construction of fences (Option 1). In this case, the parameters of the explosive device are unknown in advance and the probability of its appearance in the parking lot. Therefore, to use this or that option of the fencing layout follows from the considerations of presence of people in the possible zones of casualty. For example, if a human flow enters the affected areas, then it makes sense to use a more expensive, but correspondingly much more effective, first option for fencing layout. Otherwise, you should use the fence in the third option.

\section{Conclusions}

The article provided a general methodology for determining the effectiveness of the protective fences against explosive devices of a terroristic orientation.

An example is also provided about using the developed methodology for developing the most optimal solution for protective fences for a particular facility.

\section{References}

1. Sadovsky M.A. The mechanical effect of blast shock waves from explosions according to experimental studies - in book Blast physics., №1, M., pub. AN USSR, 1952.

2. Polandov Y., Korolchenko A., Dobrikov S. Gas explosion in a room with a window and passage to an adjacent room. (2016) MATEC Web of Conferences, 86, art. no. 04031. DOI: $10.1051 /$ matecconf $/ 20168604031$.

3. Shebeko Yu.N., Smolin I.M., Korolchenko A.Ya., Shevchuk A.P., Borodkin A.N., Malkin V.L., Simonov O.A., Gurinovich L.V., Popov S.A., Kolosov V.A., Smirnov E.V. Some aspects of fire and explosion hazards of large LPG storage vessels. (1995) Journal of Loss Prevention in the Process Industries, 8 (3), pp. 163-168. DOI: 10.1016/0950-4230(95)00011-O

4. Shebeko Yu.N., Korolchenko A.Ya., Tsarichenko S.G., Navtsenya V.Yu., Malkin V.L. Effects of the initial prssure and temperature on the combustion characteristics of hydrogen-containing mixtures. (1989) Combustion, Explosion, and Shock Waves, 25 (3), pp. 289-292. DOI: 10.1007/BF00788799 .

5. Numerical solution of multidimensional problems of gas dynamics. Edited by Godunova S.K. M. Science. 1976. P.400.

6. Komarov A.A. Forecasting impact loads from disastrous deflagrating explosions and assessing the consequences of their impact on buildings and structures. Thesis for the degree of Doctor of Technical Sciences. M. MGSU. 2001. -460p.

7. Lyapin A., Korolchenko A., Meshalkin E. Expediency of application of explosionrelief constructions to ensure explosion resistance of production buildings. (2016) MATEC Web of Conferences, 86, art. no. 04029. DOI: 10.1051/matecconf/20168604029" 
8. Korolchenko D., Voevoda S. Influence of spreading structure in an aqueous solutionhydrocarbon system on extinguishing of the flame of oil products, MATEC Web of Conferences, Volume 86, 2016, DOI: 10.1051/matecconf/20168604038.

9. Markeev V.A., Voevoda S.S., Korolchenko D.A. Fire protection of tank farm objects of Rosneft NK OAO, Neftyanoe khozyaystvo - Oil Industry Issue 9, 2006, Pages 83-85.

10. RD 03-409-01 Methodology for assessing the consequences of disastrous explosions of fuel-air mixtures. Collection of documents from ROSTECHNADZOR of Russia, SEC "Industrial Safety", series 27, issue 2. - M .: 2001. - 224 p.

11. GOST R 12.3.047-2012 SSBT "Fire safety of technological processes". -M .: GOSTSTANDART of Russia. - 85p. 